\title{
小学英语词汇教学方法探索
}

\author{
张莉梅 \\ 江西省石城县第一小学 \\ DOI:10.32629/jief.v2i9.1802
}

[摘 要] 英语词汇教学作为小学英语学习的关键, 是不可忽视的。有研究表明, 小学生模仿能力和语言天赋在这一时期表现最佳, 所以普遍 认为小学时期是学习语言的黄金时期, 这一时期的语言学习将会影响学生未来对语言的理解和掌握。所以在这一时期, 教师需要培养学生学 习英语的兴趣, 激发学生背单词的热情, 为学生拥有丰富的词汇量打下良好基础。本文通过分析小学英语词汇教学存在的问题, 指出了提高 小学英语词汇教学水平的原则和进行小学英语词汇教学的方法, 旨在帮助小学英语教师提高小学英语词汇教学水平。

[关键词] 小学英语; 词汇; 教学

中图分类号: G623.31 文献标识码: A

在小学英语词汇教学中, 存在一系列影响英语教学的问题, 进而导 致学生丧失学习英语的兴趣。因此, 如何进行有效的单词教学, 在单词 教学中如何培养学生的思维能力, 使学生主动、自觉地记单词, 是我们 每个教师应该不断思考的问题。

\section{1 目前的小学英语词汇教学中存在的问题}

1.1 单词学习目标不明确。英语课程标准中对单词的教学根据该单 词的运用频率做出了教学目标的区分, 比如有的单词仅需要认识, 有的 单词则需要记忆, 不仅能认识, 还能写出来并正确运用。然而很多教师 在具体的单词教学中, 自己都无法准确区分不同单词的教学目标, 不知 道那些单词需要重点教学和记忆, 那些单词仅仅认识即可。这就造成在 学习过程中无形加大了学生的学习量, 一些不需记忆的单词也要求学生 记忆。此外, 根据心理学的研究表明, 有重点、有区别地教学能提高教 学质量, 学生在区分下会对重点内容印象更深刻。而教师这种抹杀单词 重点和单词区别的教学方式, 使学生对单词产生厌倦情绪, 从而导致单 词教学效率低下。

1.2 剥夺语境单独讲解词义。很多教师为了教学的方便往往喜欢集 中讲解单词, 比如常用的单词教学模式就是先播放单词录音, 让学生跟 读, 然后再逐词讲解单词的意义, 让学生机械记忆单词的汉意。这种做 法, 是把单词从课文中, 从具体地英语情境中抽离出来, 机械记忆的教 学方法。学生一方面对于这种枯燥的教学模式、机械的记忆方法感到厌 烦, 丧失单词学习的兴趣, 另一方面对于单词的释义也容易流于狭隘、 浅薄, 导致很多学生虽然单词记得好, 但却不会运用的现象, 从而使我 国的学生英语运用能力非常低。比如: 单词 dark 不仅可以作名词, 表示 黑色、黑暗等意义, 还可以作形容词, 表示黑色的、无知的、神秘的等 意义。而教师传统的单词教学模式过于机械、枯燥, 只会使学生心生厌 烦, 也使单词的释义无法满足丰富的语境需要。

1.3 剥夺文化背景单独讲解词义。英语既是世界丰富多彩的语言中 的一种, 也是使用英语进行交流的民族中一种独特的文化现象。尤其是 语言和文字密不可分, 都是民族文化的载体和中介, 其中蕴含的丰富信 息自是不言而喻。然而, 我国的英语教育却仅仅把英语当作一门语言或 者工具进行教学, 而忽略了英语的人文性功能, 没能挖掘英语背后的文 化内涵。所以在我国的英语人才中才会出现很多人会说英语却不能很好 地与外国人进行交流, 这正是由于不了解中西方巨大的文化差异而造成 的。

\section{2 因地制宜,有的放矢,提高词汇教学效果}

2.1 定量识记法

小学英语教学中要求学生识记的单词较多, 而让学生完全正确掌握 是有困难的。为此, 我采用了定量识记的方法, 以 5-7 个单词为一组, 并 采用词汇卡片。这些卡片造型活泼, 色彩鲜艳, 给学生以强烈的视觉印象。 教学中, 卡片可以出现在教室的墙壁、门后、窗户玻璃上, 时时处处给学
生以印象。此外, 我让每个学生准备一个词汇卡片簿, 每天识记的单词记 在这个卡片上, 随时随地可以拿出来, 充分利用课前、娱乐、休息的时间, 培养学生时时识记的好习惯, 效果较佳。

教学中, 我随时指着单词卡片, 与学生集体复习或个别提问, 提高他 们识记的主动性, 养成学习记忆的好习惯。如人教 PEP 版六年级上册 unit one 中, 共有 36 个词汇, 其中要求学生听说读写的共有 13 个, 我将其分为 两组: “ by, foot, bike, bus, train, how ” 为一组, “go to school, traffic, traffic light, traffic rule, stop, wait, get to" 为 另一组, 学生的掌握和运用的能力大为提高。

2.2 直观教学法

小学生的思维以直观形象为主, 形象化的事物更符合小学单词识记 的心理特点, 尤其是小学英语单词多以客观事物为主。教学中, 通过直观 实物、动作、表情、卡片、学具等手段, 以生动的形式出现在学生的面前, 引导他们建立与英语词汇之间的联系, 效果较好。

例如, 英语单词实物教学, 文具类, 铅笔、尺子、橡皮等; 颜色类, 红 色、绿色、紫色、黑色等。这些都比较常见, 易于准备, 与直接去教词汇 相比较, 更容易为小学生所接受。课堂教学中, 边出示物品, 边呈现单词, 读音、拼法、词义一次完成, 直观性强, 识记效果较好, 同时还可以辅以相 关的句型练习, 如 “what is it?It” s...” 或 “I like...” 等句式, 引 导师生互相练习, 形成对单词读音、词形、词义的完整识记。

2.3 情景创造法

在适当的语言环境中运用所学的词汇, 达到学以致用, 不失为一种巩 固所学单词的好方法。在课堂教学中, 教师应尽可能地创设真实的语言情 景, 让学生身临其境地运用所学词汇。例如, 教学完有关 “Food” 的内容 时, 教师可以让学生分别扮演服务员和顾客的角色, 模拟在饭店或商场交 际的情景。又如, 教完有关 “ job” 的内容后, 教师可以让学生互相介绍自 己家人或朋友的工作。再如, 教学完有关 “Birthday” 的内容时, 教师可 以组织学生开个生日聚会, 并引导学生学习用英语表达祝愿。

综上所述, 小学英语词汇教学的方法还有很多, 如近义词法、对比教 学法、游戏竞赛法、儿歌识记法等等。在新课改理念下, 作为一名有责任 感、锐意创新的英语教师, 要不断加强学习, 借鉴优秀教育成果与先进方 法, 根据自己所带班级、学生的实际学习情况, 灵活地进行运用, 突破小学 英语词汇教学这一瓶颈, 以期达到最优化的教学效果。

\section{[参考文献]}

[1]米玉琼.小学英语翻转课堂教学模式及其有效策略 [J].科技资 讯,2020,18(06):149+151.

[2]杜金霞.小学英语翻转课堂教学模式及其应用策略 [J]. 华夏教 师,2019(36):47.

[3]梁小萍.小学英语教学中如何构建 “少教多学” 的有效课堂 [J]. 新 课程,2020(34):22. 